\title{
SUPPORT NEEDS OF UNIVERSITY ADJUNCT LECTURERS
}

Sarah M. Ginsberg, Eastern Michigan University

Little is known about the support needs of the part-time instructors on university campuses, despite the fact that they represent more than 50 percent of the instructors teaching in higher education. This study of adjunct lecturers investigated their support needs and their preferences for receiving support. Results indicated that adjuncts wanted information about their students and effective teaching methods beyond lecturing. They expressed frustration over the fact that there was no systematic approach to information sharing, particularly with the tenure-track faculty in their programs. They evenly favored resources provided either electronically or face-to-face.

Thirty-five years ago, 58 percent of faculty members were in tenure-track positions (Gappa, 2008). Fewer than half of the faculty teaching today are eligible for tenure (Gappa, 2000, 2008; Schuster, 2003; Umbach, 2006). Numerous studies, particularly at community colleges, have shed light on who these part-time instructors are, why they teach, and how they teach. However, little research has been conducted to learn what types of assistance they need and how best to deliver it. Successfully supporting the teaching of part-time faculty would seem to be critical to institutional mission and student learning outcomes.

Part-time teachers provide colleges and universities with flexibility to manage fluctuations in enrollments and decreases in government funding. The financial value of part-time instructors, typically paid less than their

This research was generously funded by the Faculty Development Center at Eastern Michigan University. 
tenure-track counterparts, cannot be overlooked. Part-time instructors typically do not get paid benefits, are paid only for the courses they teach, and do not require a commitment on the part of the institution from one semester to the next (Ellison, 2002; Gappa, 2000; Umbach, 2006).

Gappa and Leslie (1993) noted that instructors taught part time for one of four basic reasons. More than half described themselves as experts employed full time in their field, motivated to teach more by satisfaction derived from the educational process than by economic and career interests (Leslie \& Gappa, 2002). "Career enders" (p. 49) were either transitioning into retirement or had already retired. A third group chose to teach part time because of a preference for greater professional flexibility than tenure-track positions might offer. The final category was termed "aspiring academics" (p. 60): those teaching in part-time or term-limited positions, often at more than one institution at a time, in the hopes of obtaining a tenure-track position.

\section{Teaching Effectiveness and Satisfaction}

Given the financial trends in higher education, we are not likely to see a significant departure from the extensive use of adjunct lecturers in the near future. Part-time faculty not only offer the university flexibility, they bring a potentially unique quality to their classrooms. Adjunct lecturers bring realworld experience to the class that helps to ground the lessons that they teach for their students (Gappa, 2000; Nutting, 2003). They share a level of expertise, particularly in the application of concepts, that is valuable to students in many programs. Despite the low pay, lack of benefits, and limited reliability of work from one semester to the next, part-time instructors have demonstrated a remarkable dedication to their teaching positions, staying in them for an average of 6.3 years, in contrast to 11.2 years for full-time faculty (Gappa, 2000). Part-timers report having the same degree of interest in professional development activities as their fulltime counterparts (Leslie \& Gappa, 2002; Schuetz, 2002).

Studies of the instructional effectiveness of part-time instructors have yielded mixed results. Numerous studies have suggested that there is little to no difference in the instructional practices of part-time and full-time faculty (Leslie \& Gappa, 2002; Schuetz, 2002; Schuster, 2003). Findings suggest that class time use by full-time and part-time instructors is very similar; however, closer examination indicates that part-time instructors are less likely to use techniques that increase active, engaged learning such as collaboration and group activities, technology, and guest lecturers (Schuetz, 2002; Umbach, 2006). This may be partially due to their lack 
of exposure to a variety of teaching practices because they are not in an academic department full time.

Another significant distinction between full-time and part-time instructors is the amount of knowledge they hold regarding available campus services. Part-time teachers receive less orientation to their jobs than tenuretrack teachers do, which results in limited knowledge regarding resources for students, such as library services, tutoring, counseling, and extracurricular activities that support and reinforce classroom learning (Gappa, 2000; Nutting, 2003; Schuetz, 2002; Schuster, 2003). If part-time instructors are unaware of mechanisms on campus that may increase students' success, there is little likelihood that they will refer students to support resources for additional learning opportunities. This situation places the students of part-time faculty at a distinct disadvantage in comparison to students of full-time faculty.

Despite the many challenges that part-time faculty face, overall they are relatively satisfied with their teaching jobs. In comparison to their full-time faculty peers, part-time, term-limited faculty report no difference in satisfaction levels with their academic careers (Gappa, 2000, 2008; Howell \& Hoyt, 2007). It may be that part-time teachers are able to achieve their goals, which are different from those of tenure-track faculty members, through their part-time status and thus are satisfied. However, there are numerous aspects unique to the part-time teaching positions with which there is dissatisfaction, including limited notification of teaching assignments prior to the beginning of the term; poor pay compared to that of full-time teachers; few, if any, benefits; inadequate opportunities for advancement; and low status in the academic community (Gappa, 2000, 2008; Leslie \& Gappa, 2002).

\section{Our Study}

Despite our increased understanding of their numbers, their teaching effectiveness, and their job satisfaction, we know relatively little about how to help part-time faculty be more effective in their primary role as teachers. Leslie and Gappa (2002) note that "there remains a serious gap in our understanding of part-timers' teaching in community colleges" (p. 60), and even less focus has been placed on understanding adjunct lecturers teaching in universities.

\section{Methods}

This study used qualitative data collected in an individual interview format and using electronic communication with adjunct lecturers. The primary question asked of all participants was, "What areas would you like 
to receive support in to maximize your teaching effectiveness at this university?" The secondary question, asked of all participants, was their preferred format for receiving the support that they identified.

\section{Participants}

This study was conducted at a large, public university with an enrollment of twenty-three thousand students. The university employs 690 full-time, tenure-track faculty and an average of 450 adjunct lecturers for each of the two main terms of the year. Adjunct volunteers were solicited from the university's e-mail list of 457 adjunct lecturers who were teaching that term. Approximately 80 adjunct lecturers responded to the e-mail, volunteering to participate in an individual interview. It was not feasible to interview all volunteers, in large part due to the demands of the instructors' schedules. Seven adjunct lecturers were purposefully selected to represent a range of teaching experience and disciplines. The participants taught in sociology, marketing, engineering, education, theater arts, foreign languages, and chemistry programs and had been teaching at the institution for between one and eight terms. Although the sample of those interviewed is small, it reflects each major organizational division of the university. Such a naturalistic generalization (Eisner, 1998) using a smaller sample size is a common approach to guiding learning about one educational setting in order to inform our knowledge of comparable settings.

After reaching saturation by interviewing the seven adjunct lecturers, a second e-mail solicitation was sent to the remaining seventy-three individuals who had originally volunteered, offering them the opportunity to respond by e-mail to a series of questions based on the questions asked during the individual interviews. Thirty-four responded to the e-mail questions. The average number of terms that these adjunct lecturers had been teaching at this institution was ten, and again respondents represented each of the colleges within the university.

\section{Data Collection}

The face-to-face individual interviews were semistructured and focused on the primary and secondary questions. The use of interviews offered insights into each individual's perceptions and attitudes (Creswell, 2003). Because data from the electronic communication did not provide the same degree of rich detail and "thick descriptions" (Denzin \& Lincoln, 2003 , p. 98), they were used for corroborating evidence with the interview results. 


\section{Data Analysis}

Each interview was audiorecorded and then transcribed in full following Creswell's reduction and interpretation guidelines (1998). The same process was used with the written responses of the thirty-four e-mail respondents. All data were sorted sentence by sentence into categories related to concerns, comments, and needs of adjunct lecturers. These categories were then compared and consolidated into broader categories. Each unit of data, from both interviews and electronic communication, was compared with these broader categories.

\section{Results}

From our analysis of interview and e-mail data, several consistent themes emerged.

\section{“No Systematic Plan” for Information Sharing}

Despite the fact that the primary question focused on what support adjunct lecturers needed to be effective instructors, most responded by first explaining what type of support they had been given when they began teaching. All interviewed participants indicated that they were provided with "no systematic plan" for getting information about teaching. Many stated that though they knew their topic well, they knew so little about teaching that they did not know where to begin asking for help. Peter (names and identifying information have been altered to protect participant identity), who has taught an engineering course twice, stated, "I am not enough of an educator to know ... I don't know what I don't know," and he was at a loss as to what questions he should be asking. No information regarding teaching was offered by their department to any of the adjunct lecturers interviewed other than to share a copy of the syllabus from a previous semester. Dan, teaching a sociology course for the first time, was told, "We will give you full support," but he never received more than the syllabus for the course. This experience made him "feel like I'm sort of out there" on his own.

Several adjunct lecturers indicated that they took it upon themselves to gather information about teaching because they realized their department would not give them any. Bob, a retired high school drama teacher now teaching theater arts for his eighth semester, indicated that when he began, he asked for information every semester. He had to "ferret out" the information from people in the department by asking many specific questions over his first several terms of teaching. Had he not been an 
experienced teacher, he said, he would have "not known things to ask. I can imagine feeling extremely confused, disconnected, and anxious" had he not pursued this information diligently. Lidia, teaching marketing for her second term, realized that "there wasn't really any structure set up" for her to be given information about teaching. She took the initiative to seek out a tenured member of the faculty in her department and ask if she could visit his classroom several times. "We went to lunch one day, and so he's kind of been my mentor."

Lidia also had a friend who was a full-time faculty member at another institution whom she used as a resource for teaching questions. She was one of three adjunct lecturers who indicated that faculty at other universities served as a resource for teaching support. Knowledge that adjunct lecturers gained regarding teaching was due to their taking the initiative to seek out answers or initiate relationships that would provide them with mentoring. Their persistence was rewarded with information that they were seeking, but it typically gave them answers only to the questions that they knew to ask. As Dan noted, without some structured, planned orientation, he was left feeling "out there" on his own, with large gaps in his knowledge base. It was striking that the adjunct lecturers' experiences with early support made such a strong impression that they needed to share it before talking about what their current desires were.

\section{Teaching-Related Concerns}

Many adjunct lecturers were looking for skills that would improve students' in-class experience but were unable to specify what was needed. Lidia said, "I feel like I do a decent job of keeping the material interesting." But she would like to move past her reliance on lectures and "jump to the next level. ... . Those are the skills I need to develop." Eddy noted that although he knows that there are "interactive types of things" that could be done in his chemistry class, he is not familiar with alternative methods for "how you can present [information] so that they will actually understand." Lois, who has been teaching in preschools and kindergartens for over thirty years, is an instructor in the early elementary program. She feels confident about her content knowledge but would like help "gearing my teaching to people who are entering the profession" and "knowing some new things to try" to adapt her teaching skills to college students. Consistent with the literature (Schuetz, 2002), the adjunct lecturers tended to rely primarily on lectures. Nevertheless, they recognized that there are alternatives for teaching and expressed interest in gaining knowledge about new delivery methods. 
Support with grading issues was one of the most commonly identified needs. Some adjunct lecturers noted that they were uncomfortable grading anything other than multiple-choice exams and therefore avoided other forms of assessment. Dan was unsure how much latitude a teacher has in determining grades in his sociology class. He had a student who was "negotiating for grades" because despite her apparent best efforts, she was barely passing the course. He was uncertain and "could have used some guidance" in handling the challenge of a student who was trying to haggle over her grade. Adjuncts indicated that they were uncertain about how to handle common grading challenges, such as poor grammar, work turned in late, grading curves, and whether to grade for participation.

For full-time faculty, many of these issues may seem routine and obvious. However, instructors not immersed in the culture of the institution and with no regular contact with colleagues are at a disadvantage in handling common grading concerns (Schuster, 2003; Umbach, 2006). In addition, if there is a prevailing culture in a program regarding grading issues, such as whether other faculty grade participation, then the students of adjunct lecturers may be hindered by being graded by a teacher who does not grade in a manner consistent with the full-time instructors.

\section{Understanding Students}

Many participants were confused, dismayed, and caught off guard by the behaviors or characteristics of their students. Admission to this university's undergraduate program is minimally competitive: it accepts most applicants with high school diplomas. Prior to beginning his class, Eddy did not "understand the level of the student that I was going to face." Dan noted that there are "a good percentage that are really good" and impressive, but he was "shocked" by the lack of "overall academic curiosity" he saw in his students. In a discussion with a student who was struggling with a concept in his class, Dan asked if she had read the chapter. She told him, "I really don't like to read." Like most other adjunct lecturers, Dan did not understand the nature of some of the university's students, who are often working one or two jobs to put themselves through school and have family obligations in addition to their student roles.

Contributing to Dan's confusion may have been a lack of understanding of his students' majors: "I assumed that most of these [students] were going to be sociology majors. I was wrong." He soon learned that many students were in the class because his course was a core requirement for 
a number of programs. He was unprepared for the disparity in student backgrounds. Eddy was also surprised that students in his chemistry class were not chemistry majors and felt that more than half of them were not "functionally prepared for the course": "The second semester I asked [students] about their educational foundation in chemistry, and that is when it became clear to me that the majority of them were really not suitably prepared."

Because Eddy now recognizes the disparity among his students, he encourages them to succeed by talking to them about expectations for progress and learning so that they understand that they are not all starting from the same point and do not have the same goals. Peter has his engineering students write a brief biography so that he can find out how much application experience they have. Lois realized that in her early elementary teaching course, "Some people have a rich background in teaching. They've already had jobs that prepared them for teaching young people. Other people are coming right out of high school." She now begins the semester by asking the students to introduce themselves and talk about their experiences so that she understands what level of knowledge they have when they come to her class. Lois notes that it "would have been nice [to] participate in professional conversations" with members of the program's faculty to learn how to manage classes.

Given a formal orientation to the university or to the programs in which they teach, adjuncts might have been able to prepare for the heterogeneity of students' academic majors and preparation more appropriately and without the element of surprise. Despite being caught off guard in their first semester of teaching, the adjunct lecturers demonstrated a commitment to understanding more about their students so that they are able to meet their learning needs.

\section{Desired Supports}

The secondary question regarding the ideal format for the provision of support was open-ended to allow adjunct lecturers to offer suggestions of formats or modes for support delivery. Several were aware of the existence of the campus's faculty support center for teaching and suggested that the programs offered through the teaching center include them on a regular basis. They expressed interest in having a consultant watch them teach so that they could sit down and discuss their teaching. Several suggested seminars on specific topics, such as test design or active learning techniques. The possibility of "quarterly meetings" and "open forum discussions" that would allow adjunct lecturers to come together and 
discuss challenges and solutions for teaching was also raised. Those requesting face-to-face support noted that it would need to be provided either at the end of the workday, after 5:00 P.M., or on weekends. Peter suggested a weekend seminar, modeled on executive M.B.A. programs. Resources in the form of readings, either hard copy or electronic, were commonly requested.

Some adjunct lecturers indicated that although they were interested in learning more about teaching, they did not see any extra time in their schedule to attend meetings on campus. They preferred materials to be provided to them electronically so they could be accessed at their convenience. Eddy requested a "virtual toolbox ... there could be a more global tool set . . . with educational type of tools." He noted that this type of tool box would be valuable to all faculty, including adjuncts. Online courses, listservs, and videotapes were also suggested as helpful electronic forms of support. Responses were nearly equally divided between those wanting support to be provided in face-to-face formats and those wanting support to be in an electronic format. Many indicated that they would be amenable to either option.

\section{Frustrations of Being a "Necessary Evil"}

An unexpected response to the question regarding how adjunct lecturers would like to receive support was frustration about how they were treated by full-time faculty in their department. Bob noted that while there is regularly a large contingent of adjuncts teaching, "[we] feel to be somewhat of a necessary evil to the university. I think we don't feel enormously valued. ... I don't think they have enormous faith and trust in us." He observed that full-time faculty "make decisions without the input from the people that are teaching [the class] and they make decisions that are not well communicated to the people in the trenches. This to me is exceptionally shortsighted because number one you are losing a tremendous talent pool that may be very willing to assist ... and secondly, you are handing over the future of that department every semester to adjuncts who may or may not be terribly committed." Many of the adjunct lecturers who participated in the study echoed these sentiments. For some, the lack of interaction and opportunity for conversation with full-time faculty was a source of anger and frustration. Peter said, "I thought I might get invited to a faculty mix or something like that where I'm rubbing elbows with the department head, just to learn more about who the people are and all that. They haven't done any of that, so that's 
a minor disappointment." The lack of formal and informal communication between full-time and part-time faculty contributes to a sense of marginalization and low status in the professional community (Gappa, 2000, 2008; Leslie \& Gappa, 2002). Given that some of the communication missing is directly associated with teaching and curricular issues, this limited interaction may have a negative effect on student learning.

\section{Discussion}

Consistent with previous findings, the adjunct lecturers in this study felt the impact of being "unappreciated" and "undervalued," "a necessary evil" whom the university tolerates because finances and student fluctuations force it to (Gappa, 2000, 2008; Leslie \& Gappa, 2002). Remarkably, few of the comments addressed the low pay scale or the limited notice that adjuncts were given prior to teaching. The observations addressed concerns regarding limited communication between full-time and part-time faculty. Although it is clear that better communication between the two groups would ameliorate feelings of marginalization, more important to the adjunct lecturers was that the lines of communication should be open for the benefit of students in their classes. They were looking for opportunities to collaborate regarding curriculum decisions that appear logical in light of their role in the classroom.

Also compatible with the literature, the adjuncts interviewed relied primarily on lectures for teaching (Schuetz, 2002; Umbach, 2006). While Leslie and Gappa (2002) found an interest in professional development in their discipline, previous literature has not identified a desire on the part of adjunct lecturers to learn more techniques for increasing active, engaged learning. Although they were not able to identify specific methods that would improve teaching and learning in their courses, they knew that there must be alternatives to lecture available that would help them teach, "so that [students] will actually understand." These data shed new light on the awareness that part-time faculty have that there are probably pedagogical methods available and that they are looking for ways to obtain that information. Several were aware of the campus's faculty teaching center but were unaware that services offered were available to them as part-time instructors, and few mentioned resources available to assist struggling students. Our finding of their lack of awareness is congruent with other studies, which have documented the limited knowledge of campus resources for students (Gappa, 2000; Nutting, 2003; Schuetz, 2002; Schuster, 2003). Unfamiliarity with student characteristics proved to be a source of frustration 
for part-time instructors. What has not been documented in previous studies are the strategies that these adjunct lecturers reported for coping with this lack of information, such as asking for the information in introductions and written biographies.

\section{Implications and Limitations}

Despite the low pay, the unpredictability of teaching assignments, and the limited information sharing, adjunct lecturers demonstrate persistence in their willingness to teach at an institution that gives them little in return. The fact that the average respondent had been teaching for over ten semesters confirms that part-time faculty are a dedicated group (Gappa, 2000). The investment that they appear willing to make to learn about students and teaching and to work collegially with full-time faculty suggests that they are a resource worthy of cultivation.

Given the financial limitations that lead most colleges and universities to make extensive use of part-time faculty in the first place, the question remains, "How do we support adjunct lecturers?" Significant increases to pay are likely not feasible on many campuses. The literature from community colleges is replete with recommendations to increase professional development opportunities for part timers (Ellison, 2002; Thompson, 2003; Wallin, 2007). Campuses that already have a faculty teaching center can readily adapt their focus to include part-time faculty. With limited investments, programs can be redesigned specifically to meet some of the more basic needs that adjuncts have, such as dealing with grading, syllabus creation, and active teaching techniques.

Another solution to improving the teaching of adjunct lecturers that would cost little money is to increase the opportunities for communication between the full-time and part-time faculty in a program or department. Creating opportunities for formal or informal collegial interactions once or twice each semester would be of benefit to both parties and would provide adjunct lecturers with a sense of appreciation as well as an opportunity to share information with individuals who make the majority of curricular decisions. Basic orientation to the college and its students is commonly provided to the majority of permanent new faculty hires but because of the adjunct lecturers' time-limited status, this orientation is commonly overlooked (Ellison, 2002; Thompson, 2003; Wallin, 2007). Brief orientations provided at the beginning of each term could easily increase the amount of information adjuncts receive about the campus and its students that would have a direct impact on the quality of their teaching. 
New models of professional development for part-time instructors need to be explored (Wallin, 2007). The results of this study demonstrate that administrators, from those overseeing the university's human resource department to individual department heads, need to work together to provide as much information as possible to newly hired part-time faculty. Connections need to be made between part-time teachers and the campus as a whole, between part-time teachers and the department in which they teach, and, most important, between part-time teachers and their students. Staff at university teaching centers need to be inclusive of adjunct lecturers and work to make resources available to them in a variety of formats on an ongoing basis. Programs and consultations need to be offered after hours, on weekends, and electronically. Web-based formats, such as online course platforms, need to be used to provide $24 / 7$ access to those who cannot find the time to make it to campus for an extra meeting but want to learn more about teaching. Campuses that do not have their own centers for teaching and learning will face more challenges to supporting parttime teachers; however, a number of resources are available online, such as AdjunctNation (www.adjunctnation.com).

The results of this study reflect the experiences and perceptions of one group of part-time faculty at one institution. It is possible that adjuncts who responded to the opportunity to participate in this study represented a highly dedicated group of teachers. However, many of these adjuncts were in their first few terms of teaching, leaving their long-term dedication in question. It is also possible that those who did not respond had no time to learn more about teaching. The large number of individuals who responded to the offer of study participation may have been motivated to do so in hopes of having their voices heard on a topic that is important to them. The sample interviewed in this study was representative of the university's individual colleges and a wide range of disciplines; however, it was a small sample. Even when combining the written responses from the thirty-four e-mail participants with those of the seven interviewees, the sample remains but a small percentage (just under 10 percent) of adjunct lecturers on this particular campus at the time. Future practices would be aided by larger-scale studies at a variety of universities. Although the views and experiences of this group may not generalize to all institutions, they do provide a place to begin the conversation about how to improve the teaching of part-time instructors and thus improve the learning of their many perhaps hundreds of thousands, or more, students. 


\section{REFERENCES}

Creswell, J. N. (1998). Qualitative inquiry and research design: Choosing among five traditions. Thousand Oaks, CA: Sage.

Creswell, J. N. (2003). Research design: Qualitative, quantitative, and mixed methods approaches (2nd ed.). Thousand Oaks, CA: Sage.

Denzin, N. K., \& Lincoln, Y. S. (2003). Collecting and interpreting qualitative materials. Thousand Oaks, CA: Sage.

Eisner, E. W. (1998). The enlightened eye: Qualitative inquiry and the enhancement of educational practice. Upper Saddle River, NJ: Prentice Hall.

Ellison, A. (2002). The accidental faculty: Adjunct instructors in community colleges. Tampa: University of South Florida. (ERIC Document Reproduction Service No. ED466874)

Gappa, J. M. (2000). The new faculty majority: Somewhat satisfied but not eligible for tenure. In L. S. Hagedorn (Ed.), New directions for institutional research: No. 105. What contributes to job satisfaction among faculty and staff (pp. 77-86). San Francisco: Jossey Bass.

Gappa, J. M. (2008). Today's majority: Faculty outside the tenure system. Change, 40(4), 50-54.

Gappa, J. M., \& Leslie, D. W. (1993). The invisible faculty. San Francisco: Jossey-Bass.

Howell, S. L., \& Hoyt, J. (2007). Part-time faculty job satisfaction in higher education: A literature review. Provo, UT: Brigham Young University. (ERIC Document Reproduction Service No. ED499387)

Leslie, D. W., \& Gappa, J. M. (2002). Part-time faculty: Competent and committed. In C. L. Outcalt (Ed.), New directions for community colleges: No. 118. Community college faculty: Characteristics, practices, and challenges (pp. 59-67). San Francisco: Jossey-Bass.

Nutting, M. M. (2003). Part-time faculty: Why should we care? In E. Benjamin (Ed.), New directions for higher education: No. 123. Exploring the role of contingent instructional staff in undergraduate learning (pp. 33-39). San Francisco: Jossey-Bass.

Schuetz, P. (2002). Instructional practices of part-time and full-time faculty. In C. L. Outcalt (Ed.), New directions for community colleges: No. 118. Community college faculty: Characteristics, practices, and challenges (pp. 39-46). San Francisco: Jossey-Bass.

Schuster, J. H. (2003). The faculty makeover: What does it mean for students? In E. Benjamin (Ed.), New directions for higher education: No. 123. Exploring the role of contingent instructional staff in undergraduate learning (pp. 15-22). San Francisco: Jossey-Bass. 
Thompson, K. (2003). Contingent faculty and student learning: Welcome to the strativersity. In E. Benjamin (Ed.), New directions for higher education: No. 123. Exploring the role of contingent instructional staff in undergraduate learning (pp. 41-47). San Francisco: Jossey-Bass.

Umbach, P. D. (2006). How effective are they? Exploring the impact of contingent faculty on undergraduate education. Review of Higher Education, 30(2), 91-123.

Wallin, D. L. (2007). Part-time faculty and professional development: Notes from the field. In R. L. Wagoner (Ed.), New directions for community colleges: No 140. The current landscape and changing perspectives of part-time faculty (pp. 67-73). San Francisco: Jossey-Bass. 